\title{
A PESQUISA-AÇÃO CRÍTICA NO DESENVOLVIMENTO DE POLÍTICAS DE FORMAÇÃO CONTINUADA PARA PROFISSIONAIS DA EDUCAÇÃO
}

\author{
INVESTIGACIÓN DE ACCIÓN CRÍTICA EN EL DESARROLLO DE POLÍTICAS DE \\ FORMACIÓN CONTINUA PARA PROFESIONALES DE LA EDUCACIÓN
}

\author{
CRITICAL ACTION RESEARCH IN THE DEVELOPMENT OF CONTINUING \\ TRAINING POLICIES FOR EDUCATION PROFESSIONALS
}

\author{
Mariangela Lima de ALMEIDA ${ }^{1}$ \\ Rafael Carlos QUEIROZ ${ }^{2}$ \\ Maria Assunção FLORES ${ }^{3}$ \\ Diana Alexandra Ribeiro PEREIRA ${ }^{4}$
}

RESUMO: Este artigo objetiva analisar as contribuições da pesquisa-ação para o desenvolvimento de políticas de formação continuada de profissionais da educação pela via da autorreflexão crítica. Apresenta um diálogo entre estudos na área de formação de professores e resultados de uma pesquisa-ação colaborativo-crítica voltada à construção de políticas de formação continuada para os profissionais da educação realizada por meio da colaboração entre Universidade e Redes de Ensinos do Espírito Santo/Brasil. Problematiza o grupo de estudo-reflexão como princípio para elaboração de modos críticos de formação continuada. Estabelece um diálogo entre autores da literatura científica e autores do contexto, promovendo a construção de conhecimentos com o outro. Toma os argumentos dos gestores em diferentes momentos do Grupo de Estudo-Reflexão de Gestão de Educação Especial (Gergees), constituídos por meio de narrativas audiovisuais e transcrições de encontros do grupo. Analisa a busca pela autorreflexão crítica e colaborativa como possibilidades de outros/novos modos de conceber e produzir conhecimentos. Assim, defende a formação de profissionais sustentada na pesquisa-ação crítica como princípio para o desenvolvimento de políticas de formação continuada em contextos locais.

PALAVRAS-CHAVE: Políticas de formação continuada de profissionais da educação. Gestão em educação especial. Pesquisa-ação colaborativo-crítica.

${ }^{1}$ Universidade Federal do Espírito Santo (UFES), Vitória - ES - Brasil. Professora Adjunta do Centro de Educação. Doutorado em Educação (UFES). ORCID: https://orcid.org/0000-0002-7092-2583. E-mail: mlalmeida.ufes@gmail.com

${ }^{2}$ Universidade Federal do Espírito Santo (UFES), Vitória - ES - Brasil. Mestrando no Programa de PósGraduação de Mestrado Profissional em Educação (PPGMPE). ORCID: https://orcid.org/0000-0002-4428-1081. E-mail: rafaelqueiroz6@yahoo.com.br

3 Universidade do Minho (UMINHO), Braga - Portugal. Professora Auxiliar do Instituto de Educação. Doutorado em Educação (NOTTINGHAM) - Inglaterra. ORCID: https://orcid.org/0000-0002-4698-7483. Email: aflores@ie.uminho.pt

4 Universidade do Minho (UMINHO), Braga - Portugal. Professora Auxiliar do Instituto de Educação. Doutoramento em Ciências da Educação (UMINHO) - Portugal. ORCID: https://orcid.org/0000-0002-35501855. E-mail: dianapereira@ie.uminho.pt 
RESUMEN: Este artículo tiene como objetivo analizar las contribuciones de la investigación-acción al desarrollo de politicas de educación continua para profesionales de la educación a través de la autorreflexión crítica. Presenta un diálogo entre estudios en el área de formación docente y los resultados de una investigación acción colaborativa-crítica dirigida a construir politicas de educación continua para profesionales de la educación realizada a través de la colaboración entre la Universidad y las Redes Docentes de Espirito Santo / Brasil. Cuestiona el grupo de estudio-reflexión como principio para la elaboración de modos críticos de educación continua. Establece un diálogo entre autores de la literatura científica y autores del contexto, promoviendo la construcción del conocimiento con el otro. Toma los argumentos de los responsables en diferentes momentos del Grupo de EstudioReflexión sobre Gestión de la Educación Especial (Gergees), constituido a través de narrativas audiovisuales y transcripciones de reuniones grupales. Se analiza la búsqueda de posibilidades de autorreflexión crítica y colaborativa de otras/nuevas formas de concebir y producir conocimiento. Así, la formación de profesionales basada en la investigación-acción crítica se aboga como un principio para el desarrollo de políticas de educación continua en contextos locales.

PALABRAS CLAVE: Políticas de formación contínua de los profesionales de la educación. Gestión de educación especial. Investigación-acción colaborativa-crítica.

ABSTRACT: This article aims at analyzing the contributions of action research to the development of continuing education policies for education professionals through critical self-reflection. It presents a dialogue between studies in the area of teacher education and the findings from a collaborative-critical action research aimed at building continuing education policies for education professionals carried out through collaboration between the University and Teaching Networks of Espirito Santo/Brazil. It questions the study-reflection group as a principle for the elaboration of critical modes of continuing education. It establishes a dialogue between authors of the scientific literature and authors of the context, promoting the joint construction of knowledge. It takes the arguments of the managers at different moments of the Study-Reflection Group on Special Education Management (Gergees), constituted through audio-visual narratives and transcripts of group meetings. The search for critical and collaborative self-reflection possibilities of other / new ways of conceiving and producing knowledge is analyzed. Thus, the education of professionals based on critical action research is advocated as a principle for the development of continuing education policies in local contexts.

KEYWORDS: Policies for continuing education of education professionals. Special education management. Collaborative-critical action research.

\section{Reflexões iniciais}

Os movimentos sociais, políticos e educacionais ocorridos nas últimas décadas, em diferentes cenários, trazem consigo a procura por uma proposta inclusiva na educação, assumindo o princípio da educação para todos (BRASIL, 2008; BANCO MUNDIAL, 2012; PORTUGAL, 2018). A busca pela construção de espaços-tempos que deem conta de lidar 
com a complexidade do cotidiano escolar, marcado pela diferença e pela diversidade humana, impõe-nos a necessidade de repensar a formação dos profissionais da educação e seus impactos nas práticas escolares e nas aprendizagens dos alunos (DARLING-HAMMOND; NEWTON; WEI, 2010; FLORES, 2016; FRANCO; PIMENTA, 2008).

Nessa perspectiva, a literatura aponta para a necessidade de associarmos a pesquisa (SACHS, 2016) ao fortalecimento da profissão docente, assumindo esses profissionais como produtores de conhecimento. Para tanto, buscamos uma visão sociocrítica do desenvolvimento profissional e da formação de profissionais da educação, concebendo-os como intelectuais transformadores (GIROUX, 1997). Nesse sentido, é fundamental considerar que os currículos de formação continuada de profissionais da educação devem ser elaborados pela e para a investigação (ESTEVES, 2006).

Pesquisa-ação, nesse entendimento, tem se constituído como abordagem metodológica e epistemológica essencial, considerando que se trata de uma atividade empreendida por grupos com o objetivo de modificar suas circunstâncias a partir de valores humanos partilhados. Nesse sentido, “[...] tal formação está inserida e só pode ser compreendida no contexto social, político, econômico e cultural do país que a promove, destacando, portanto, a importância dos aspectos contextuais na formação profissional do professorado" (ZEICHNER, 1998, p. 238).

Desta forma, o presente artigo objetiva analisar as contribuições da pesquisa-ação para o desenvolvimento de políticas de formação continuada de profissionais da educação pela via da autorreflexão crítica. Enfatiza o lugar da gestão de Educação Especial na elaboração e transformação das políticas de formação continuada voltadas para a inclusão escolar. Para tanto, esse profissional precisa "[...] apreendê-las no âmbito das relações sociais em que se forjam as condições para sua proposição e materialidade" (DOURADO, 2007, p. 922).

O texto apresenta um diálogo entre estudos na área de formação de professores resultados de uma pesquisa-ação colaborativo-crítica voltada à construção de políticas de formação continuada para os profissionais da educação, desenvolvida por meio da colaboração entre Universidade e Redes de Ensinos do Espírito Santo/Brasil instituída pela parceria entre professores/alunos da universidade e gestores ${ }^{5}$ públicos de Educação Especial.

Temos como premissa que, seja no contexto de produção dos textos das políticas de formação continuada, seja no contexto da prática, os gestores se constituem como

\footnotetext{
${ }^{5} \mathrm{Na}$ pesquisa apresentada neste artigo, os gestores de Educação Especial são os profissionais/técnicos que atuam nas Secretarias de Educação, como membro ou como coordenador do setor responsável pelas políticas de Educação Especial.
} 
articuladores e mediadores das ações políticas nos munícipios e/ou regiões em que atuam. Concordamos com Paro (1998, p. 4), quando afirma que o processo de gestão/administração desempenhado por esse gestor tem em sua essência a característica da "[...] mediação na busca de objetivos". Assim, a compreensão do lugar que se ocupa como gestor nas políticas educacionais se torna fundamental. Situamo-nos também na perspectiva de Ball, para quem a política não é simplesmente implementada; trata-se de uma atuação, envolvendo valores locais e pessoais. Nessa perspectiva:

[...] pertence ao contexto de influência, porque é parte do ciclo do processo através do qual as políticas são mudadas, ou podem ser mudadas ou, pelo menos, o pensamento sobre as políticas muda ou pode ser mudado. O pensar sobre as políticas e o discurso das políticas podem ser mudados pela ação política (MAINARDES; MARCONDES, 2009, p. 306).

Assim, embora os gestores muitas vezes se concebam como meros executores das políticas, eles ocupam lugar de grande importância no contexto de influência e da prática das políticas. Nesse sentido, temos defendido a formação de gestores públicos como elemento crucial no desenvolvimento de políticas de formação continuada de profissionais da educação pela via da pesquisa-ação crítica.

Conforme Carr e Kemmis (1988), a pesquisa-ação crítica constitui-se como uma investigação emancipatória que vincula teoria e prática à crítica, em um processo que se ocupa simultaneamente da ação e da investigação. Nesse sentido, a pesquisa educacional crítica tem como meta o autoconhecimento consciente e a ação política eficaz. Seu método é o diálogo, que tem como objetivo elevar a autoconsciência dos sujeitos como potencial coletivo, como agentes ativos na história (COMSTOCK, 1982 apud CARR; KEMMIS, 1988). Concordamos com Habermas (1987b, p. 140):

O enquadramento metodológico que estabelece o sentido de validade desta categoria de enunciados críticos avalia-se pelo conceito de auto-reflexão. Esta liberta o sujeito da dependência de poderes hipostasiados ${ }^{6}$. A autoreflexão está determinada por um interesse emancipatório do conhecimento. As ciências de orientação crítica partilham-no com a filosofia.

Nesse contexto, acreditamos que, a partir da autorreflexão crítica, gestores e equipe da universidade possam constituir-se em uma comunidade autocrítica de pesquisadores que investigam suas concepções e ações, em busca da compreensão e transformação das políticas postas em suas localidades.

6 Os poderes hipostasiados descritos por Habermas (1987b) podemos compreender como aqueles fixos e congelados que se apresentam como naturais nas relações sociais.

RIAEE - Revista Ibero-Americana de Estudos em Educação, Araraquara, v. 16, n. esp. 2, p. 1199-1214, maio 2021. e-ISSN: 1982-5587 
Neste artigo, nossa intenção é estabelecer um diálogo entre autores da literatura científica e autores do contexto - gestores e profissionais da universidade. Nosso objetivo é, pela tessitura dessa discussão, analisar as contribuições da pesquisa-ação para a construção de políticas de formação continuada na perspectiva da inclusão escolar, elaboradas por gestores de Educação Especial. Ao mesmo tempo, desejamos problematizar o grupo de estudo-reflexão como princípio para elaboração de modos críticos de formação continuada. Dessa forma, nossa perspectiva de análise tem como premissa que:

No lugar do sujeito solitário, que se volta para objetos e que, na reflexão, se toma a si mesmo por objeto, entra não somente a ideia de um conhecimento linguisticamente mediatizado e relacionado com o agir, mas também o nexo da prática e da comunicação quotidianas, no qual estão inseridas as operações cognitivas que têm desde a origem um caráter intersubjetivo e ao mesmo tempo cooperativo (HABERMAS, 2003, p. 25).

Buscamos, assim, a construção de conhecimentos com o outro. Tomamos os argumentos dos gestores em diferentes momentos do Grupo de Estudo-Reflexão de Gestão de Educação Especial (Gergees) ${ }^{7}$, constituídos por meio de narrativas audiovisuais e transcrições de encontros do grupo. Assim, motivados pela possibilidade de constituir uma comunidade intersubjetiva com base na fala argumentativa, estabelecemos espaços discursivos com os gestores-autores acerca das políticas de formação continuada em seus contextos locais e o lugar que ocupam nos contextos de elaboração, influência e prática dessas políticas.

\section{Da racionalidade instrumental à comunicativa: perspectivas e políticas de formação continuada de profissionais da educação}

Neste item, temos como objetivo discutir os desafios postos aos modos como temos concebido e desenvolvido políticas públicas de formação de profissionais da educação em uma perspectiva da inclusão escolar. Podemos dizer que esses têm sido os dois principais objetos de análise e discussão do Gergees.

Concordamos com Habermas (1987a, p. 24, grifo nosso, tradução nossa) que diz que "[...] a racionalidade tem menos a ver com o conhecimento, ou com a aquisição de conhecimento, e mais com a forma como os sujeitos capazes de linguagem e de ação fazem uso do conhecimento". O pensamento habermasiano proporciona-nos analisar o modo como os conhecimentos e os saberes são utilizados nas práticas e nas pesquisas sociais/educacionais. Podemos, assim, dizer que as epistemologias e as metodologias para a

7 O grupo inicia-se em 2013 como uma das ações de pesquisa e extensão do Grupo de Pesquisa Formação, Pesquisa-ação e Gestão de Educação Especial (Grufopees/CNPq/UFES). 
formação de profissionais da educação são constituídas pelas formas como os sujeitos se apropriam do conhecimento e como o utilizam nas diferentes iniciativas e proposições formativas.

É importante considerar que, na racionalidade cognitivo-instrumental, não há uma relação direta entre ouvinte e falante (HABERMAS, 1987a). Podemos perceber que as formações, nessa perspectiva, em grande parte, são concebidas sem diálogo com as demandas de seus participantes, com a realidade educativa e/ou escolar, como relatam os gestores:

São oferecidas algumas formações em meu município, porém muitas com palestras técnicas já preestabelecidas (GESTORA MUNICIPAL, 2019).

Essa provocação que eu tenho tido, que vem de uma formação até tradicional, uma formação tecnicista, ela me chegou através de muito estudo [...] (GESTORA ESTADUAL, 2019).

Os processos, assim concebidos, desconsideram os atores do contexto como produtores de conhecimentos. A marca do enraizamento positivista, concretizado no modelo do professor técnico, desprovido de reflexão e crítica, conduz muitos docentes, ainda nos dias de hoje. Observamos que "[...] quando participam de uma formação, vão à procura de receitas prontas” (GESTORA MUNICIPAL, 2019) ou de certificação para contabilização de pontos em processos seletivos. Derivada exclusivamente de regras, a teoria, nessa perspectiva, assume o significado de solucionar os problemas da prática a partir de questões instrumentais prescritas pelo conhecimento científico.

Em muitos contextos, a formação continuada de profissionais da educação continua a privilegiar metodologias baseadas na racionalidade técnico-instrumental (SILVA, 2000), destacando o papel do formador em detrimento do papel reflexivo, crítico e participativo dos formandos (profissionais).

Muitas vezes o professor vai em busca da acumulação de certificados porque sabe que, no processo seletivo, aquilo vai beneficiá-lo, então também é algo para ser refletido [...]. O professor vai lá e faz o curso durante o ano, ganha o certificado, passa no processo seletivo e, quando retorna, ele fala que não está preparado?! (GESTOR ESCOLAR E MESTRANDO, 2019).

Embora registrem evoluções interessantes numa linha de uma racionalidade prática e crítica que se assenta nos contextos e nos seus protagonistas com vista à sua transformação, a verdade é que continuam a existir resistências e dificuldades, muitas vezes associadas à assunção de um papel mais passivo por parte das pessoas em formação e à exterioridade da formação, sobretudo quando ela é imposta e ligada diretamente à progressão na carreira. 
Uma política pública de formação continuada envolve identificar “[...] processos de resistência, acomodações, subterfúgios e conformismo dentro e entre as arenas da prática, e o delineamento de conflitos e disparidades entre os discursos nessas arenas" (MAINARDES, 2006, p. 50). Por vezes, os discursos estavam omissos, ocultados ou silenciados. Assim, a reprodução de termos, sem a devida reflexão ou apreensão de concepções e de ideias, pode levar os gestores a cair nas armadilhas dos contextos de influência em que as políticas públicas educacionais são produzidas, ou seja, os contextos nos quais os "[...] grupos de interesse disputam para influenciar a definição das finalidades sociais da educação e do que significa ser educado" (MAINARDES, 2006, p. 51).

Nesse sentido, o processo de mecanização disseminado nas formações e no trabalho do gestor escamoteia os reais princípios e pressupostos dos currículos de formação de professores, os quais, em sua maioria, se sustentam na racionalidade instrumental. Racionalidade essa fortemente marcada por políticas neoliberais, em que instituições como o Banco Mundial têm sido um dos mais importantes veículos de divulgação da racionalidade técnica e científica em reformas educacionais e, mais especificadamente, na formação de professores no mundo (PEREIRA, 2002).

[...] desenvolvemos elou participamos, ao longo de nossa história de educadores, de uma formação continuada previamente estabelecida, ou seja, não passamos por um processo de construção crítico-reflexivo e isso nos tornou também 'menos críticos' $e$, até certo ponto, 'acomodados' (GESTORA ESTADUAL, 2015).

Ao refletir sobre as bases que sustentam os processos formativos que tem praticado e participado, a gestora coloca para si e para o grupo o desafio de outros modos de pensar a formação continuada. Como gestores públicos de Educação Especial, atuam diretamente nos contextos de produção do texto e no contexto da prática das políticas públicas de formação continuada (BALL; BOWE, 1992 apud MAINARDES, 2006). Ocupando o lugar de elaboradores ou praticantes da política, os gestores apontam os desafios postos à necessidade de uma outra racionalidade da ação nos processos formativos:

[...] creio que é possível avançar um pouco mais nos processos de formação realizados no âmbito da Superintendência de Cachoeiro, principalmente no que se refere às parcerias e ao processo de escuta aos profissionais da Educação Especial (GESTORA ESTADUAL, 2014).

[...] compreendo que tal processo vem para desafiar os docentes a serem agentes de seu próprio percurso de formação (GESTORA MUNICIPAL, 2016). 
É nesse sentido que acreditamos em uma política pública de formação continuada que desafie gestores e professores como produtores de conhecimentos. Ou seja, que está “[...] sujeita à interpretação e recriação e onde a política produz efeitos e consequências que podem representar mudanças e transformações significativas na política original" (BOWE, 1992 apud MAINARDES, 2006, p. 53).

Portanto, uma política que se sustente em parcerias e no processo de escuta aos profissionais, sustentada por uma racionalidade da ação que se afasta de planos que almejam a verdade do saber, para poder realizar um fim desejado, que busca manipular e se adaptar inteligentemente às condições de um contexto contingente (HABERMAS, 1987a). Uma política formativa que valorize a reflexão crítica como potenciadora das práticas profissionais, da construção de saberes, da identidade profissional e do desenvolvimento profissional impulsionadas pelas

[...] práticas de formação contínua de professores, as quais deverão integrar não só a racionalidade técnica, mas também a racionalidade prática e crítica que permitam aos formandos - aos professores - a sua atualização contínua, não exclusivamente numa perspectiva de aquisição (de conhecimentos, de qualificações), mas fundamentalmente de desenvolvimento profissional e pessoal (SILVA, 2000, p. 104).

Acreditamos, assim, em políticas que possam se sustentar em uma racionalidade comunicativa que, para Habermas (1987a), mantém uma interação direta com o ouvinte na busca pelo entendimento mútuo.

Inicialmente, nós juntamos a SRE Afonso Cláudio, Brejetuba e Laranja da Terra na concepção que a gente tinha no momento de que o primeiro passo era alcançar os diretores, os pedagogos que estavam nas escolas, no entendimento de que se eles não têm uma concepção formada do que é Educação Especial. Se eles não acreditam, não vão produzir também junto com os professores (GESTOR MUNICIPAL, 2014).

É possível observar outro modo de propor e elaborar políticas, numa outra racionalidade, em que se busca, com o outro (gestores públicos, bem como os atores da escola), entendimentos e acordos. Evidenciamos, nessa perspectiva, um saber que é suscetível à crítica, pois será racional, se o falante se fizer entender ao ouvinte. Essa forma de utilizar o saber:

[...] possui conotações que, em última instância, remontam à experiência central da capacidade de concordar sem coações e gerar consensos com base numa fala argumentativa em que os diversos participantes superam a subjetividade inicial de seus respectivos pontos de vista e, graças a um conjunto de convicções racionalmente motivado, se asseguram, por sua vez,

RIAEE - Revista Ibero-Americana de Estudos em Educação, Araraquara, v. 16, n. esp. 2, p. 1199-1214, maio 2021. e-ISSN: 1982-5587 
de uma unidade do mundo objetivo e da intersubjetividade do contexto em que desenvolvem suas vidas (HABERMAS, 1987a, p. 27, tradução nossa).

É nesse movimento que falaremos das possibilidades que temos vivido e experimentado como grupo. No próximo item, nos dedicaremos à reflexão e discussão acerca das nossas buscas por outros/novos modos de conceber/produzir conhecimentos e constituir processos formativos para profissionais da educação.

\section{As possibilidades vivenciadas pela via da pesquisa-ação colaborativo-crítica}

Temos apostado no potencial dos grupos para buscar romper com a lógica de produção neoliberal e instrumental na construção de conhecimentos sobre políticas educacionais e formação de profissionais na perspectiva da inclusão de alunos público-alvo da Educação Especial. Dessa forma, assumimos a pesquisa-ação em seus princípios epistemológicos e metodológicos como opção política na construção de conhecimentos com o outro e não sobre o outro. Esse movimento possibilita-nos delinear as configurações do grupo de estudoreflexão composto por gestores e professores das redes de ensino do Espírito Santo e professores e alunos da universidade.

Nos anos de 2018 e 2019, o Gergees dedicou-se a estudos sistemáticos sobre a pesquisa-ação e suas contribuições para as políticas de formação continuada nas redes de ensino do Espírito Santo. As demandas são permanentemente dialogadas, o que propicia ao grupo identificar suas prioridades diante das necessidades que se colocam nos contextos locais de atuação dos gestores.

Pesquisadora Universitária 1: Eu até anotei, ao longo da discussão, várias coisas que eu vi. Eu anotei assim olha: a questão do PDI como estratégia para a formação do professor de Educação Especial, a questão da política de formação e das condições de trabalho docente, currículo escolar e as suas implicações para a formação continuada de professores e alguns aspectos da formação, por exemplo, trabalhar com a resistência do outro [...]. A concepção de autorreflexão crítica, de escuta sensivel em Barbier eu vejo como duas estratégias [...].

Gestora Municipal 1: Resistência! Porque leva para um lado atitudinal. O que você vai fazer para quebrar essa resistência desses profissionais, para eles estarem abertos a aprender. Eu acho que vai muito de encontro à formação continuada e à escuta sensivel.

Gestora Municipal 2: Escuta sensivel! 
Podemos observar no diálogo a negociação das demandas do grupo naquele momento, buscando processos formativos acerca da formação de professores. Os argumentos postos nos espaços discursivos dos encontros do grupo são negociados num constante processo de escuta sensível (BARBIER, 2007) em busca dos entendimentos mútuos.

Conforme os gestores partilham no grupo, a escuta sensível possibilita as primeiras ações de mudança nas redes de ensino, em relação às políticas de formação continuada docente, uma vez que os profissionais assumem o lugar de coautores do processo vivido, transformando as suas realidades (FRANCO, 2015).

O que é a escuta sensivel? Ela trata de um escutar-ver. Escuta sensivel se apoia na empatia com o outro (PESQUISADOR UNIVERSITÁRIO, 2019).

Então, assim sobre pesquisa-ação, ele [autor do texto estudado] traz os conceitos, que parece uma coisa muito fácil de ir lá estudar, mas não é. É muito complexo! Porque não é somente um recorte do real, do que você está vendo. E comunga muito com uma escuta sensivel que envolve todos os sentidos, todas as percepções (GESTORA MUNICIPAL, 2019).

A partir deste momento que a gente tem esse espaço de escuta e de fala, você consegue envolver todos os personagens, todos esses autores que estão no contexto da educação (GESTORA MUNICIPAL, 2019).

Segundo Habermas (2004), quando os sujeitos pensam e argumentam sobre diferentes questões, a teoria do agir comunicativo coloca-se com vista ao entendimento mútuo entre os sujeitos. Assim, temos nos posicionado permanentemente diante do desafio de construir, colaborativamente, no grupo, modos de organização de nossa própria aprendizagem e de nossos processos de conscientização (HABERMAS, 2004). Temos observado que o estudo prévio da produção científica, a organização da mediação dos encontros, o espaço aberto para que todos possam colocar seus argumentos, a escuta sensível e a autorreflexão crítica (individual/coletiva) têm se constituído como importantes ferramentas epistemológicas e metodológicas durantes nossos encontros.

Gestora Municipal 1: A gente trouxe umas questões [...] que a gente tem feito parte, já tem um tempo já, do grupo de pesquisa. Em relação à formação continuada dos profissionais [...], a gente buscou a conceituação, a origem mesmo de onde vem e de onde deriva a palavra formação, então trata-se de uma ação e de um efeito de se formar, dar forma, construir algo, tratando-se de duas ou mais pessoas ou coisas compondo um todo do qual são parte [...].

Pesquisadora Universitária 1: Onde você buscou isso? É um autor português, né? 
Gestora Municipal 1: Sim, eu só não me lembro o nome [...]. Nossos colegas costumam colocar para a gente quando se trata de educação inclusiva e educação especial. É a mesma pergunta, e é a mesma afirmação: 'Eu não tive formação para atender este aluno' [...].

Pesquisadora Universitária 2: [...] infelizmente esse discurso ainda se reverbera e, quando a gente vai fazendo alguma proposição interessante, eles pegam e falam: 'Mas o especialista é você!' [...].

Esse trecho traz um dos momentos de um encontro em que o planejamento da mediação de grupo foi realizado por um mestrando e duas gestoras. No encontro anterior, havia sido definida a temática e cada membro do grupo se responsabilizou em buscar textos sobre o tema. Assim, o aprofundamento da literatura científica, bem como o adensamento teórico no diálogo com a reflexão crítica das práticas vividas vão possibilitando ao grupo produzir conhecimentos colaborativamente. Buscamos, então, constituir com os gestores uma comunidade autocrítica voltada à autorreflexão organizada. Como nos dizem Carr e Kemmis (1988, p. 161, tradução nossa), uma “[...] ciência social crítica que versa sobre a práxis social [...] a ser empreendida por grupos autorreflexivos preocupados em organizar sua própria prática à luz de sua autorreflexão organizada”.

A partir do compromisso dos gestores com o próprio processo de aprendizagem e da consequente participação ativa de todos, construímos, colaborativamente, o processo formativo do grupo. O grupo promove o espaço discursivo de acordo com os pressupostos adotados: a comunicação se dá livre de pressões ou hierarquias, "[...] afinal, se todos os membros não puderam participar plenamente da discussão, não será possível assegurar que as conclusões alcançadas representem na realidade o melhor do pensamento do grupo" (CARR; KEMMIS, 1988, p. 160, tradução nossa). Esse espaço discursivo é rico em argumentos, possibilitando o diálogo entre os pares, promovendo a identidade profissional dos gestores num processo de implicação como pesquisadores (BARBIER, 1985) e convertendo os atores em autores no processo de construção (CARR; KEMMIS, 1988).

Gestora Municipal 1: E ai quando a gente traz essa discussão, a gente se remete a essa formação, destacando o quanto ela é importante nessas questões, porque, a partir desse momento que a gente tem esse espaço de escuta e de fala, você consegue envolver todos os personagens, todos esses autores que estão no contexto da educação [...].

Gestora Municipal 2: $O$ interessante é que lá [no municipio], existe o Conselho de Professores, porque lá o pedagogo tinha a prática de criar os projetos e entregar para os professores, e, então, quando a gente começou a formação, eles nos cobraram o tempo todo: 'Mas vocês não vão dar nada? Vocês não vão dar apostilas para a gente?' [...]. 
Gestora Municipal 1: E a pesquisa-ação ela traz isso, ela ensinou isso tudo para a gente, porque a gente também foi treinado para isto, para receber uma formação continuada pronta e fechadinha, com os seus módulos bonitinhos [...]. Então esse movimento da pesquisa-ação ele quebra todo o paradigma dessa questão, de que o individuo tem que vir prontinho [...] esse movimento da pesquisa-ação vai na contramão de tudo isso, né? Ele faz com que realmente você repense suas práticas e realmente busque conhecimento pela troca [...].

Dessa forma, a pesquisa-ação apresenta-se como uma maneira de fazer com o outro, de modo que todos reflitam criticamente sobre suas práticas, construindo, assim, outras/novas possibilidades de trabalho, das quais todos fazem parte e participam do processo formativo, não como coadjuvantes, mas como autores das decisões e da própria investigação. Percebemos, então, no grupo de estudo-reflexão, um princípio fundante na estratégia de organização do grupo: a colaboração no processo de construção de conhecimento sobre as políticas de formação continuada. No lugar do sujeito/grupo solitário que se debruça sobre seu objeto de investigação ou o seu problema, temos um sujeito/grupo coletivo, isto é, os "amigos-críticos" (CARR; KEMMIS, 1988) que buscam o entendimento mútuo, a compreensão de si mesmo, do outro e da realidade. Nesse movimento, percebemos a ação comunicativa que Habermas (1987a, p. 285-286) defende e explica que isso acontece:

[...] sempre que as ações dos sujeitos envolvidos são coordenadas, não através de cálculos egocêntricos de sucesso, mas através de atos de alcançar o entendimento. $\mathrm{Na}$ ação comunicativa, os participantes não estão orientados primeiramente para o seu próprio sucesso individual, eles buscam seus objetivos individuais respeitando a condição de que podem harmonizar seus planos de ação sobre as bases de uma definição comum de situação. Assim, a negociação da definição de situação é um elemento essencial do complemento interpretativo requerido pela ação comunicativa.

Assim, os gestores de Educação Especial, comprometidos com seus próprios processos de aprendizagem, colocam-se em movimentos de autorreflexão colaborativo-crítica sobre as políticas de formação continuada, buscando interpretar e transformar suas práticas e realidades locais, envolvendo-se, portanto, num processo formativo de cunho emancipatório (CARR; KEMMIS, 1988; HABERMAS, 2000).

Como resultado deste diálogo, percebemos as contribuições da pesquisa-ação que se revelam nas potencialidades da parceria entre universidade e redes de ensino, constituída na mediação entre teoria e prática. Os desafios são muitos, as tensões e os conflitos inerentes ao grupo se presentificam ao longo dessa trajetória do Gergees. Contudo, temos buscado nos constituir numa comunidade autocrítica de pesquisadores preocupados com sua prática social 
e envolvidos em uma "[...] comunicação orientada para o entendimento mútuo e o consenso [provisório], para uma tomada de decisões justa e democrática e para uma ação comum que satisfaça a todos" (CARR; KEMMIS, 1988, p. 210, tradução nossa).

\section{Do processo vivido... algumas considerações}

Desse processo vivido muitas possibilidades têm sido constituídas acerca das políticas públicas de formação continuada nas redes de ensino do Espírito Santo. A pesquisa-ação tem sido incorporada pelos gestores nos processos formativos em seus locais de atuação.

[...] é importante o processo de pesquisa-ação no meu lócus de trabalho, principalmente no que tange à perspectiva colaborativo-crítica, porque, a partir do momento em que a Universidade abriu suas portas para que nós, gestores, atuantes na Educação Especial em nossos municípios, pudéssemos adentrar e nos embebedar dos conhecimentos teóricos e epistemológicos, foi de suma importância. A pesquisa-ação entrou, emergiu também no nosso espaço de trabalho [...] (GESTORA MUNICIPAL, 2019).

Percebemos a real importância do processo colaborativo e potencialidades-potência da parceria entre universidade e redes de ensino, aproximando a tão necessária relação teoriaprática, possibilitando que os gestores trabalhassem nessa perspectiva em seus contextos, tendo os professores como autores de seus próprios processos formativos.

Diante desse processo individual de autorreflexão crítica, os gestores realizaram um processo de formação continuada de profissionais constituído a partir da escuta e da negociação com os atores do contexto. O diálogo no grupo nos mostra as possibilidades de desenvolver processos formativos a partir do entendimento mútuo, quando os atores buscam harmonizar internamente seus objetivos e ações com acordos alcançados comunicativamente (HABERMAS, 2003).

Uma das ações que nasceram desse grupo de estudo foi a nossa formação continuada, que é totalmente advinda da perspectiva da pesquisa-ação colaborativo-crítica, ou seja, nossa formação é constituída pelos profissionais da Secretaria de Educação, onde os próprios profissionais elaboram, juntamente com nós, equipe gestora, as temáticas que serão desenvolvidas no decorrer dessa formação, ou seja, todas as temáticas são advindas do chão da escola, das realidades vivenciadas nas unidades de ensino (GESTORA MUNICIPAL, 2019).

Temos buscado, pelos princípios do diálogo, da colaboração e da autorreflexão crítica, um movimento concomitante em que, ao mesmo tempo em que os gestores buscam compreender e construir propostas de formação continuada para os profissionais de suas redes 
de ensino, desenvolvem sua própria formação em um processo de "formar formando-se" (PANTALEÃO, 2009), essencial à própria dinâmica da pesquisa-ação colaborativo-crítica.

[...] Falando um pouco agora da minha implicação e da minha trajetória como gestora, que passou por todo o processo formativo desse grupo de pesquisa, [...] foi de extrema importância não só para me constituir como profissional apenas, mas também, aos poucos, eu pude estar presenciando e também me constituindo como pesquisadora. Ou seja, com o decorrer dos encontros e dos estudos desse aprofundamento, eu pude também emergir e me implicar no contexto de pesquisadora/investigadora [...] (GESTORA MUNICIPAL, 2019).

Das pistas que temos encontrado nesse caminho, parece-nos que os momentos de diálogos entre os gestores, nesse processo de constituição dos grupos de estudo-reflexão, possibilitaram a construção de um sentimento coletivo de querer fazer, envolvendo-os enquanto pesquisadores. É certo que estamos envolvidos, melhor, implicados como nos diz Barbier (1985).

Os movimentos dos gestores no processo de pesquisa, suas concepções sobre o que é uma formação reflexivo-crítica, suas consequências para a melhoria da qualidade educacional e a elaboração de políticas de formação inclusiva reverberam no modo como eles têm se colocado como gestores-pesquisadores. Com uma conduta de luta política, fica claro o processo de emancipação que vem sendo trilhado durante o percurso do grupo de estudoreflexão e sua visão do que é ser gestor público de Educação Especial.

Diante disso, as reflexões trazidas neste texto dão conta de uma experiência de mudança envolvendo os participantes na decisão sobre o sentido da sua própria formação. Trata-se, sem dúvidas, de uma implicação estrutural-profissional, que encontra sentido a cada encontro do grupo, na nossa constituição como pesquisadores e na crença na produção de conhecimentos. É por esse caminho que defendemos a formação de gestores sustentada na pesquisa-ação crítica como princípio para o desenvolvimento de políticas de formação continuada de profissionais da educação, em contextos locais, de modo que se constituam como superação dos modelos técnicos e instrumentais.

\section{REFERÊNCIAS}

BANCO MUNDIAL. Relatório mundial sobre a deficiência. São Paulo: SEDPcD, 2012.

BARBIER, R. A pesquisa-ação na instituição educativa. Rio de Janeiro: Ed. Jorge Zahar, 1985. 
BARBIER, R. A pesquisa-ação. Brasília: Liber Livro, 2007.

BRASIL. Ministério da Educação. Política nacional de educação especial na perspectiva da educação inclusiva. Brasilia, DF, 2008.

CARR, W.; KEMMIS, S. Teoría crítica de la enseñanza: la investigación-acción en la formación del profesorado. Trad. J. A. Bravo. Barcelona: Martinez Roca, 1988.

DARLING-HAMMOND, L.; NEWTON, X.; WEI, R. C. Evaluating teacher education outcomes: a study of the Stanford Teacher Education Programme. Journal of Education for Teaching, v. 36, n. 4, p. 369-388, 2010.

DOURADO, L. F. Políticas e gestão da educação básica no Brasil: limites e perspectivas. Educação e Sociedade, Campinas, v. 28, n. 100, p. 921-946, out. 2007. DOI: https://doi.org/10.1590/S0101-73302007000300014

ESTEVES, M. Análise de conteúdo. In: LIMA, J. A; PACHECO, J. A. (Org.). Fazer investigação: contributos para a elaboração de dissertações e teses. Porto: Porto Editora, 2006.

FLORES, M. A. Teacher education curriculum. In: LOUGHRAN, J; HAMILTON, M. L. (Ed.). International handbook of teacher education. Dordrecht: Springer Press, 2016.

FRANCO, M. A. S. Práticas pedagógicas de ensinar-aprender: por entre resistências e resignações. Educ. Pesqui., São Paulo, v. 41, n. 3, p. 601-614, jul./set. 2015.

FRANCO, M. A. S.; PIMENTA, S. G. (Org.). Pesquisa em educação: Possibilidades investigativas/formativas da pesquisa-ação. São Paulo: Loyola, 2008.

GIROUX, H. A. Os professores como intelectuais: rumo a uma pedagogia crítica da aprendizagem. Tradução de Daniel Bueno. Porto Alegre: Artes Médicas, 1997.

HABERMAS, J. Teoría de la acción comunicativa: racionalidad de la acción y racionalización social. Version de Manuel Jimenez Redondo. Madrid: Taurus, 1987a.

HABERMAS, J. Técnica e ciência como ideologia. Tradução de Artur Morão. Lisboa: Edições 70, 1987b.

HABERMAS, J. Teoría y práxis: estudios de filosofia social. Trad. Salvador Mas Torres y Carlos Moya Espí. 4. ed. Madrid: Tecnos, 2000.

HABERMAS, J. Consciência moral e agir comunicativo. 2. ed. Rio de Janeiro: Tempo Brasileiro, 2003.

HABERMAS, J. Verdade e justificação: ensaios filosóficos. Tradução de Milton Camargo Mota. São Paulo: Loyola, 2004.

MAINARDES, J. Abordagem do Ciclo de Políticas: uma contribuição para a análise de políticas educacionais. Educação e Sociedade, Campinas, v. 27, n. 94, p. 47-69, jan./abr. 2006. DOI: https://doi.org/10.1590/S0101-73302006000100003 
MAINARDES, J.; MARCONDES, M. I. Entrevista com Stephen J. Ball: um diálogo sobre justiça social, pesquisa e política educacional. Educação e Sociedade, Campinas, v. 30, n. 106, p. 303-318, jan./abr. 2009. DOI: http://dx.doi.org/10.1590/S0101-73302009000100015

PANTALEÃO, E. Formar formando-se nos processos de gestão e inclusão escolar. 2009. Tese (Doutorado em Educação) - Programa de Pós-Graduação em Educação, Universidade Federal do Espírito Santo, Vitória, 2009.

PARO, V. H. A gestão da educação ante as exigências de qualidade e produtividade da escola pública. São Paulo: Ed. Vozes, 1998.

PEREIRA, J.E.D. A pesquisa dos educadores como estratégia para construção de modelos críticos de formação docente. In: PEREIRA, J.E.D.; ZEICHNER, K.M. (Org.). A pesquisa na formação e no trabalho docente. Belo Horizonte: Autêntica, 2002.

PORTUGAL. Ministério da Educação. Decreto-Lei n. 54/2018, de 6 de julho. Diário da República, n. 129/2018, Série I, 2018

SACHS, J. Aprender para melhorar ou melhorar a aprendizagem: o dilema do desenvolvimento profissional contínuo dos professores. In: FLORES, M. A.; SIMÃO, A. M. V. (Org.). Aprendizagem e desenvolvimento profissional de Professores: contextos e perspectivas. Mangualde: Edições Pedago, 2016.

SILVA, A. M. C. A formação contínua de professores: uma reflexão sobre as práticas e as práticas de reflexão em formação. Educação e Sociedade, Campinas, v. 21, n. 72, p. 89-109, ago. 2000. DOI: http://dx.doi.org/10.1590/S0101-73302000000300006

ZEICHNER, K. M. Para além da divisão entre professor-pesquisador e pesquisador acadêmico. In: GERALDI, C.; FIORENTINI, D.; PEREIRA, E. M. A. (Org.). Cartografias do trabalho docente. Campinas: Mercado de Letras, 1998.

\section{Como referenciar este artigo}

ALMEIDA, M. L.; QUEIROZ, R. C.; FLORES, M. A.; PEREIRA, D. A. R. A pesquisa-ação crítica no desenvolvimento de políticas de formação continuada para profissionais da educação. Revista Ibero-Americana de Estudos em Educação, v. 16, n. esp. 2, p. 11991214, maio 2021. e-ISSN: 1982-5587. DOI: https://doi.org/10.21723/riaee.v16iesp2.15121

Submissão em: $15 / 12 / 2020$

Revisões requeridas em: 28/01/2021

Aprovado em: 03/03/2021

Publicado em: 01/05/2021 